\title{
Present problems and controversies concerning pregnant adolescents
}

\author{
This article was published in the following Dove Press journal: \\ Open Access Journal of Contraception \\ I I April 201 I \\ Number of times this article has been viewed
}

\author{
Faustino R Pérez-López' \\ Peter Chedraui ${ }^{2,4}$ \\ Amy S Kravitz ${ }^{3}$ \\ Danny Salazar-Pousada ${ }^{2}$ \\ Luis Hidalgo ${ }^{4}$ \\ 'Department of Obstetrics and \\ Gynaecology, Facultad de Medicina, \\ Universidad de Zaragoza, Hospital \\ Clínico, Zaragoza, Spain; ${ }^{2}$ High Risk \\ Pregnancy Labor and Delivery Unit, \\ Hospital Gineco-Obstétrico Enrique \\ C. Sotomayor, Guayaquil, Ecuador; \\ ${ }^{3}$ Jay Weiss Center of Social Medicine \\ and Global Health Equity, University \\ of Miami, FL, USA; ${ }^{4}$ Facultad de \\ Ciencias Médicas, Universidad \\ Católica de Guayaquil, Guayaquil, \\ Ecuador
}

Correspondence: Faustino R Pérez-López Department of Obstetrics and Gynaecology, Facultad de Medicina, Universidad de Zaragoza, Hospital Clínico, Domingo Miral s/n, Zaragoza 5009, Spain

Fax +34976761735

Email faustino.perez@unizar.es

\begin{abstract}
Pregnancy during adolescence is a very vulnerable aspect of human reproduction. Multiple studies from around the world show the increased burden of pregnancy on adolescent females compared to their adult counterparts, with adverse outcomes for both mother and child including anemia, preterm delivery and low birth weight. Adverse obstetrical outcomes have been related to socio-economic status, physical immaturity and ongoing maternal growth, and nutritional status. Negative aspects related to pregnancy may be mitigated with an optimal health care system targeting certain areas within this specific population, such as socio-economic and family support, treatment of infections, adequate nutrition, appropriate management of labor and the implementation of intervention programs (both before and after birth). Preventing subsequent pregnancies in adolescent mothers should be a major medical and social goal. This manuscript will review updated information regarding the risks related to adolescent pregnancies.
\end{abstract}

Keywords: adolescent, pregnancy, preterm birth, low birth weight

\section{Introduction}

An adolescent pregnancy is a significant public health issue, and can lead to multiple, complex, and often controversial obstetrical problems. Adolescent pregnancy is strongly associated with adverse living conditions for both parents and infants in later life, and pregnant adolescents should be considered a high risk-group of people who require special care to fulfill their needs. Risk factors contributing to pregnancy in adolescence include precocious sexual activity, poor school performance, economic disadvantage, being the offspring of single or teen parents, and a prior adolescent pregnancy. Prevalence of pregnancy during adolescence is high in both developed and non developed regions of the world. ${ }^{1-3}$ Healthcare differences for this high risk group, such as discrepancies between demands and availability, are often dictated by local regulation, cultural factors and economic standards.

Younger adolescents (aged 16 or less) are more likely to have unplanned sexual intercourse and be coerced into sex than their older counterparts. More than half of adolescent pregnancies occur in those aged 18 to 19 , which is considered legal adulthood in many countries. Pregnant teenagers face many of the same obstetrical issues as women in their $20 \mathrm{~s}$ and $30 \mathrm{~s}$, but there are additional medical concerns for younger mothers, particularly those under 16 years of age and living in developing countries. ${ }^{4-7}$ Adolescent childbirth-related maternal deaths have barely changed in two decades. ${ }^{8}$ For mothers between 15 and 19, age itself is not considered a risk factor, but rather is a confounder for additional risk factors related to socio-economic status, incomplete pubertal development, and nutrition factors. ${ }^{3,9,10}$ The aim of the present manuscript is 
to perform an updated review of the risks related to pregnancy in adolescents.

\section{Risk factors for adolescent pregnancies}

Factors increasing pregnancy among teenagers are numerous (Figure 1), and may vary between populations. Low contraceptive use among teens may increase pregnancy rates among them, despite the increase in detailed information and availability of contraception. ${ }^{11}$ Increasing rates of unplanned sex among adolescents and the fact that emergency contraception is not always available can be seen as additional risk factors for pregnancies in this population. Social, educational and racial inequity can increase the risk of adolescent pregnancies, thereby amplifying their social vulnerability and the risk of obstetrical complications. ${ }^{3,12}$ Poorly educated adolescents and those with a poor family structure are at higher risk for unwanted pregnancies (Figure 1). It has been shown that adolescents who are actively involved in their education and eager to achieve their scholastic goals tend to place less emphasis on sexual relations. ${ }^{4}$ In this regard, adolescents with less than 12 years of schooling are more likely to give birth by the age 18 as compared to those with more schooling. ${ }^{11}$ However, wanted pregnancies before the age of 20 years are part of the culture of some communities, in spite of the similar obstetrical complications that may result in both planned and unplanned pregnancies.

Results from around the world show alarming trends in pregnancies and abortions in this group. In the United States, while the teen birth rate showed a promising drop of $34 \%$ from 1991 to 2005, rates again increased by 5\% between 2005 and $2007 .{ }^{13}$ Further, during this time, unplanned pregnancies resulted in a significant number of abortions. ${ }^{14} \mathrm{~A}$ recent report regarding the evolution of European families gives detailed information concerning unplanned pregnancies. It showed that adolescent pregnancy rates in the United Kingdom have increased over the past decade, and that half of all pregnancies among girls aged less than 18 ended in abortion. The Young People's Development Program was abandoned after finding that it was not decreasing the number of pregnancies among adolescents. However, the greatest increase in abortion is occurring in Spain, rising from 49,578 in 1997 to 112,138 in $2007 .{ }^{15}$ In Ecuador, as an example of a Latin American situation, 20\% of women aged 15 to 19 get pregnant before age $20 .^{3,16-18}$ In this population segment there are inequities between adolescent girls regarding educational levels, geographical regions, and household income. For example, among girls with high school education, there was an $11 \%$ pregnancy rate, compared to a rate of $43 \%$ in illiterate girls lacking formal education. There are also differences in adolescent pregnancy rates among different Ecuadorian regions. ${ }^{19}$

\section{Obstetrical risk in the pregnant adolescent}

A major problem for the pregnant teen relates to her own body, and the degree of both physical and emotional development achieved during the pubertal process. The incomplete development of the genital tract and the musculoskeletal system of pregnant adolescents predisposes them to worse

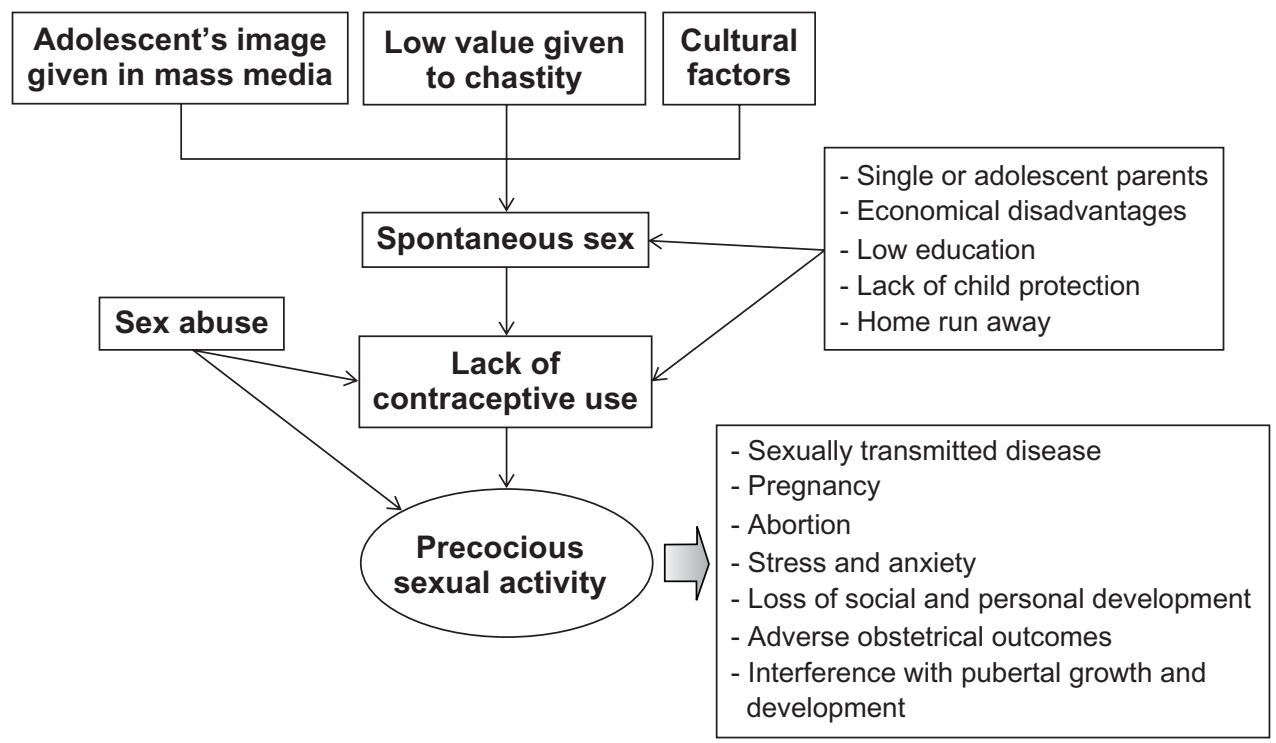

Figure I Adolescent pregnancy: risk factors and consequences. 
overall obstetrical outcomes. There are higher rates of spontaneous abortions, preterm delivery, and low birth weight in girls under age 16 as compared to older adolescents and women aged 20-29. ${ }^{20,21}$ Furthermore, complications of pregnancy lead to twice as many deaths in adolescents compared to adult women. ${ }^{11,22}$ In Latin America, maternal mortality among adolescents 16 or less is four times that of women aged $20-24 .{ }^{23}$ In addition to the increased maternal mortality rates, pregnancy can induce tremendous psychological stress on the adolescent, particularly with undesired pregnancies. The associated psychological and emotional burdens can be due to factors that include the additional perinatal and economic responsibilities, adjustment in lifestyle and changes in the family dynamic. The evolution of, and solution to, these conflicts may vary, and can have a lifelong impact.

It seems obvious that pregnancy in adolescence can have a profound psychological impact, with new stresses that continue well into adulthood. There is evidence, moreover, that many pregnant adolescents have recognizable stressors even prior to their pregnancies. As reported by Mollbom and Morningstar, ${ }^{24}$ the combination of poverty and existing distress was a good predictor of teen pregnancy. To prevent this problem, there is a need for the family unit to promote self-esteem in the adolescent, and to encourage the development of long term goals. A recent study performed in Ecuador found that pregnant adolescents presented with a high rate of depressive symptoms and displayed a lower level of resilience compared to gravids aged 20 to $30 .{ }^{25}$

Major physical risks associated with adolescent pregnancies include anemia, preterm labor and hypertension-related complications, including eclampsia. Compared to women aged 19 or more, pregnant adolescents initiate prenatal care later, have fewer visits, use abortive procedures more frequently and have higher rates of prematurity and low birth weight. While adolescents do predominately have vaginal deliveries, they more frequently have vaginal tears, require instrumental deliveries and have infants with low neonatal Apgar scores. ${ }^{26-28}$ The increased incidence in unfavorable obstetric outcomes in adolescents is seen irrespective of health system. In the Netherlands, which has a high quality prenatal care system, teenage gravids have less favorable outcomes than older women, including a 1.5 times higher rate of preterm delivery. Compared to older women, the risk of intrauterine death showed a 4-fold increase among those aged 13-17 and a doubling among those aged 18-19 years. These figures were similar for those with Dutch ancestry and those of foreign descent, demonstrating consistency across cultural and racial lines. In the Dutch population, deliveries among adolescents were predominately spontaneous and less often assisted as compared to women older than 19 years. $^{29}$

In a multiethnic American study, teenage gravids also showed increased rates of unfavorable obstetric outcomes. As compared to their older counterparts, teens showed a two-fold increase in the risk of experiencing pregnancyrelated hypertension, as well as an increased rate of low birth weight infants born at term (defined as infants weighing less than 2,500 grams at 38 weeks). Rather than age, the most important predictor of pregnancy outcome was the number of antenatal visits..$^{30}$ An additional American study, however, showed some discrepant findings regarding obstetric conditions and outcomes within the adolescent population. This study showed no significant difference between primigravid teens aged $<16$ and women between the ages of 18-29 for most antenatal complications, including hypertension, placental abruption, placenta previa, premature rupture of membranes, urinary tract infections and anemia. ${ }^{31}$

There have been consistent findings seen with targeted and comprehensive care plans, which have demonstrated improved outcomes with adolescents. A meta-analysis ${ }^{32}$ assessed behavioral risk factors in teenagers and compared outcomes with a traditional prenatal care plan versus a more robust, comprehensive care plan. The risk of pregnancyinduced hypertension was lower in those patients assigned to the comprehensive care cohort as compared those with conventional care. In addition, the comprehensive care reduced modifiable risk factors in teens. ${ }^{32} \mathrm{~A}$ more recent study demonstrated that an adequate prenatal care plan may decrease the incidence of conditions such as anemia and hypertension in teenagers. ${ }^{33}$

The importance of reducing modifiable risk factors is clear, as tobacco, alcohol and/or illicit drug consumption during pregnancy are implicated in neonatal complications. Tobacco is the drug most frequently used during pregnancy, followed by alcohol and cannabis, with other illicit substances less commonly used. Mothers using drugs during pregnancy have been found to be more likely to delay initiation of prenatal care and present at an advanced gestational age. ${ }^{34}$ Alcohol consumption during pregnancy is a well known risk factor for poor birth outcomes, including fetal alcohol syndrome, birth defects, and low birth weight. However, in the majority of adolescent populations, alcohol and other social drugs are not a common serious concern. . $^{31,35,36}$

Teenage primigravidae are more likely to have a spontaneous vaginal delivery, without compromising maternal or neonatal outcome. However, when pathological conditions such as anemia, pre-eclampsia or eclampsia are encountered 
in girls of age 16 years or less, cesarean section rates increase when compared to older adolescents. Skeletal development, including height and body weight, may influence the cesarean rate.

Outcomes in teenage pregnancies differ according to ethnic, economic and cultural conditions. A recent crosssectional Australian study looking at the obstetrical and perinatal outcomes of teenagers compared to adult women has shown significant differences between ethnic populations. ${ }^{37}$ Indigenous women have a higher rate of pregnancy than non-indigenous women, with more associated risk factors, including anemia and tobacco use.$^{37}$ Although perinatal outcomes for teenage and adult women appeared similar, after adjusting for confounding factors, preterm delivery, admission to special care nursery and low birthweight were more prevalent within the indigenous population. ${ }^{37}$ These results suggest the need for targeted interventions in order to provide appropriate and effective care. This could include earlier detection and treatment of anemia, improved nutritional assessments and the encouragement of a healthy lifestyle with abstinence from tobacco and alcohol.

\section{Nutrition and weight in pregnant adolescents}

Nutrition is pivotal for fetal growth, and is directly related to maternal anthropometry and placental volume. ${ }^{38}$ Low maternal weight and body mass index at conception or delivery, and poor weight gain during pregnancy, have been associated with low birth weight, prematurity, and maternal delivery complications. ${ }^{39}$ Few women at the beginning of their pregnancy have healthy life style habits and an appropriate diet. ${ }^{40}$ This is particularly pertinent for adolescents, in whom most pregnancies tend to be unplanned. It would be anticipated that adolescents commence their pregnancy with deficiencies of nutrients such as folic acid, iodine, vitamin D, and protein. Moreover, as literature reports indicate, dietary patterns tend to change very little during the course of the pregnancy as compared to the preconceptional period. ${ }^{41}$ Thus, dietary deficiency tends to increase as gestation advances. The impact of nutrition and weight on pregnancy is well known and maternal weight gain is the most important determinant of infant weight in adolescent pregnancies. Nutritional requirements for the pregnant adolescent are further increased not only to meet the needs of the pregnancy and growing fetus, but also for the mother's own pubertal development. In essence, a competition for nutrients may be established between the developing fetus and the mother who has still not fully matured. ${ }^{32}$ Adolescents who begin pregnancy underweight, (body mass index $<19.8 \mathrm{~kg} / \mathrm{m}^{2}$ ) are significantly impacted and have a two-fold increased risk for pre-term delivery. ${ }^{42}$ In addition to complications associated with low baseline weight in this population, inadequate maternal weight gain, defined as less than $9 \mathrm{~kg}$, significantly increases the risk of delivering lighter infants (2,942 grams versus 3,392 grams), as well as the prevalence of low birth weight infants, defined as those less than 2500 grams (13\% versus 1\%). Furthermore, adolescents with low weight gain during pregnancy have the greatest risk of delivering children with low birth weight. Several factors causing low maternal weight gain have been identified and include physical maternal abuse, sexually transmitted disease (STD) during pregnancy, and undesired pregnancies. ${ }^{43}$ Interestingly, certain socio-economic factors including parity, school attendance, marital status, employment and poverty level were not found to influence weight gain.

As a group, pregnant adolescents also have shorter stature at the time of conception as compared to adult pregnant women. This difference may be due to several factors, including physical immaturity, and malnutrition. During pregnancy, there is physiological adjustment of resting energy in adolescents, with the cession of height growth. ${ }^{44}$ Teen mothers with short stature have an increased risk for smaller infants (lower weight and length), a finding which is independent of maternal age within this group. ${ }^{45,46}$ Adolescents with a height measurement below the 10th percentile have a higher risk for obstetric complications during pregnancy. ${ }^{47,48}$ However, it seems that short stature is not as strong as a predictor of adverse perinatal outcomes as is low weight. ${ }^{49}$

Teenage mothers are at nearly three times higher risk of having anemia. ${ }^{50}$ Anemia is of great obstetric concern as the condition is associated with several complications including low birth weight and increased risk of preterm delivery. ${ }^{51-53}$ While the causes of anemia are multifactorial, it is commonly associated with deficient nutrition, such as lack of iron or B12, and general infections in certain impoverished populations and less developed regions of the world. These nutritional deficiencies can be present in poor and rich countries. Both iron deficiency and the anemia that it induces are very frequent in pregnant adolescents, and require appropriate interventions to reduce complications. ${ }^{54,55}$ It has been postulated that iron deficiency, via induction of hypoxia and norepinephrine increase, can induce an immunoendocrine stress response, as expressed by corticotrophin releasing hormone $(\mathrm{CRH})$ increase during preterm labor, pregnancy-induced hypertension, eclampsia and premature rupture of the amniotic membranes. ${ }^{56}$ It has been reported that high $\mathrm{CRH}$ concentrations are associated with preterm 
birth. ${ }^{57}$ Prolonged periods of fasting increase CRH secretion, and inverse correlations have been reported between maternal $\mathrm{CRH}$ levels and gestational age at delivery. ${ }^{58}$ It is theorized that adequate nutritional intake could decrease the $\mathrm{CRH}$ response and hence contribute to reducing the stress response in pregnant adolescents. Furthermore, pregnant adolescents reaching delivery with anemia can be at higher risk in the event of postpartum hemorrhage during or after labor.

Of additional nutritional concern during pregnancy are decreased vitamin D serum levels. Deficiency of vitamin D is very common during pregnancy, even in sunny regions, ${ }^{59}$ and is attributed to low dietary intake. Low serum vitamin D levels have been associated with numerous adverse obstetrical conditions, including low birth weight, pre-eclampsia, gestational diabetes and neurological disorders. ${ }^{60,61}$ This is of particular importance to adolescents, as low vitamin D levels are often seen in puberty. ${ }^{62}$ If pregnancy occurs, this may worsen as a result of fetal growth and maternal development. However, data regarding vitamin D in pregnant adolescents and recommendations for its use are lacking.

Identification and correction of all the aforementioned nutritional deficiencies may significantly decrease deficiencyrelated risks during pregnancy such as inadequate weight gain and anemia, hence improving perinatal outcomes. To minimize risk to the fetus and mother, adolescents require an optimal healthy diet in order to gain at least $9 \mathrm{~kg}$ with sufficient amounts of essential minerals and vitamins to ensure normal maternal development and appropriate fetal growth. Due to the increased risks for pregnant adolescents, prenatal visits for this population should be more frequent than in conventional obstetrical care, and should involve implementing a comprehensive service for nutritional guidance, healthy life style habits and psycho-emotional support.

\section{Preterm birth}

Mechanisms involved in the initiation of normal labor at term are not completely understood. During normal pregnancy, there are normal increases in pituitary and placental sources of CRH as well as in its RNA messenger expression. These progressively increasing levels stimulate maternal and fetal pituitary adrenocorticotropic hormone (ACTH) secretion and fetal adrenal gland dehydroepiandrosterone sulfate release. ${ }^{63}$ $\mathrm{CRH}$ is also a strong local regulator of myometrial contractility and membrane prostaglandin release, and the role of $\mathrm{CRH}$ and other cytokines in preterm labor is complex and not fully understood. Preterm labor has been associated with a number of factors including genital tract infections, extra-genital chronic inflammation, stress, and lifestyle factors, ${ }^{64-70}$ which may be stronger determinants in pregnant adolescents than in adult pregnant women. In young adolescents ( $<16$ years), anatomical characteristics of the cervix (specifically the short cervix) would favor preterm delivery. ${ }^{71}$

Preterm birth is of particular concern as it contributes to higher infant mortality and morbidity rates in adolescent mothers. Investigations have shown that young maternal age in both developed and developing countries is associated with an increased risk of preterm delivery. While increased preterm delivery is more prevalent in adolescents, it remains unclear whether this association disappears after adjusting for socio-economic and educational factors. ${ }^{32}$

In a Canadian cohort, preterm delivery was found to be more prevalent in adolescents as compared to older women, although smoking rather than maternal age was seen as the strongest independent predictor. In this study, low birth weight was more frequent among adolescents than in the older age group, although decreased gestational age was found to be the most important correlate in younger pregnancies. Anemia was also significantly associated with poor perinatal outcomes. ${ }^{64}$ Comparison of primiparous adolescents and primiparous women aged 20-24 years showed significant differences in the rate of preterm delivery (less than 33 completed weeks), with a doubling of the risk for those 16-17 and a quadrupling of risk for those aged 13-15. Rates for preterm births (33-36 completed weeks) were similar between the subgroups of adolescents. ${ }^{72}$

One important factor linked to pre-term delivery is infection. Lower genital tract infections are very frequent among pregnant adolescents due to multiple factors, including fewer and lower quality prenatal visits, difficulties in completing treatment due to economics and low compliance, lack of family support, and poor sexual hygiene. Untreated genital tract infections may lead to an increased risk of preterm delivery through immune alterations. Treatment of vulvovaginitis and vaginosis in particular has been shown to reduce this associated risk. ${ }^{67} \mathrm{~A}$ common condition, bacterial vaginosis $(\mathrm{BV})$, has been linked to poor outcomes during pregnancy, including an association with preterm delivery, low birth weight, perinatal infections and adverse outcomes. These associations with adverse outcomes are particularly concerning due to the ubiquity of BV in some populations. A Danish study investigated the relation of BV on pregnancy and found a prevalence of $16 \%$ detectable before 20 weeks gestation. Further correlation of BV to obstetrical outcome demonstrated a significantly lower mean infant birth weight in those with BV than in those without. Multivariate analyses after adjustment for several confounding factors confirmed 
that BV was associated with preterm delivery, low birth weight, preterm delivery of a low-birthweight infant, and clinical chorioamnionitis. ${ }^{73}$

In addition to infections of the genital tract, infections of the urinary tract are also implicated in adverse outcomes. Pregnant women with urinary tract infections also had significantly higher rates of intrauterine growth restriction, preterm birth, pre-eclampsia and cesarean deliveries. ${ }^{70}$ In macaque monkeys links have been reported between Ureaplasma parvum and Mycoplasma hominis and chorioamnionitis and preterm deliveries. ${ }^{74}$ Periodontitis may also negatively affect pregnancy. ${ }^{68}$

The physiological relation between infection and inflammation and the induction of early delivery is considered to be due to linkage to the immunoendocrine response of preterm labor. ${ }^{75}$ The immunoendocrine response is a common biological response to pregnancy stress, tied into the bio-psycho-social stress that the condition imposes on the adolescent overall. Overall, pregnant adolescents with unwanted pregnancies have an increased propensity for genital infections and tend to have social and economical difficulties. With the negative impact of stress and anxiety on pregnancy, it seems that these additional stressors may increase the risk of preterm delivery, and inversely affect gestation length. ${ }^{66,76,77}$ In fact, the majority of women who deliver at term have lower levels of stress and anxiety than those who deliver preterm. Although this may differ in the overall pregnant population and is related to differences in socio-economic factors, in general stress initiates a generalized common immune-endocrine response. Despite this, the adolescent endocrine and immune systems may be regulated at different set points than non-adolescent pregnant women. Specific studies defining these changes among adolescent pregnant women are lacking.

\section{Labor and delivery}

There are controversial (and sometimes unfounded) opinions regarding labor and delivery in adolescents. In a series of 239 primiparas aged $<16$ years the incidence of cesarean section and lacerations during vaginal delivery was significantly lower as compared to primiparas aged $18-29 .{ }^{31}$ cesarean section rate in adolescent nulliparous term pregnancies has been reported to be lower than nulliparous adult women, ${ }^{25,31,78,79}$ or similar. ${ }^{80}$ However, there are also reports pointing out higher cesarean section rates among adolescents, ${ }^{81,82}$ preventing any clear conclusion being drawn.

One study showed that while labor characteristics and intrapartum/puerperal complications in nulliparous adolescents aged 15 or less were similar to nulliparous women aged 20 to 30 , these adolescents did display a higher risk of cervico-vaginal infections, low birth weight infants and adverse neonatal outcomes. ${ }^{80}$ Another report confirmed the lack of divergence in complication rates between the two groups, with similar results for fetal presentation and mode of delivery, as well as, contrary to the above study, similar rates of infections during delivery and rates of premature rupture of membranes. ${ }^{82}$ A decreased rate of laceration during vaginal delivery amongst adolescents was found by Perry et al, ${ }^{31}$ a finding supported by other subsequent research. ${ }^{26-28}$

Height, skeletal morphology and calcification seem to influence gestational duration and the progress of labor. In adult Asian women classified by quartiles, maternal height influenced the rate of preterm birth. ${ }^{83}$ This data confirms that amongst Asian adolescents, immature maternal physical development may be a risk factor for preterm delivery, ${ }^{84}$ results which are applicable outside this ethnic population, and are consistent with previous findings. In addition, there was a significant increase in the cesarean section rate due to mechanical causes, despite the higher incidence of small for dates and low birth weight infants. ${ }^{85}$ This effect seems to be a continuous process not triggered by a specific height cut-off. Maternal height is probably a significant factor contributing to shorter gestation duration and increased number of cesarean sections in pregnant adolescents. Indications for a cesarean section, however, remain quite subjective among obstetricians.

Just as decreased maternal development can negatively affect fetal outcome, it can also affect pregnancy and lactation. Pregnancy and lactation during adolescence impose a negative effect on the pubertal process, disrupting normal linear growth and producing weight loss and depletion of fat, minerals, vitamins and lean body mass in young girls. As a result, the adolescent's growth and development is negatively impacted, with long-term implications for general health and future pregnancies..$^{10,62,86}$

A recent Indian cross-sectional study supported the relationship between maternal height, obstetrical outcome, and socio-economical variables. This study found that for every additional centimeter in maternal height, there was a significant reduction in child mortality, delivery of underweight infants, stunting, wasting and anemia, whereas paternal height was not associated with child mortality. ${ }^{87}$

Finally, throughout the stages of labor, there have been differences found in the use of pain medications in adolescents. Labor pain management and obstetric regional anesthesia are used less common in primiparous adolescents than in primiparous women over age $19 .{ }^{88}$ Some obstetrical centers request written consent before administrating labor analgesia to adolescents for vaginal delivery. In many centers, pregnant teens 
are not permitted to give medical or surgical consent, therefore consent must be obtained from their medical proxy, typically their parents or legal guardian. ${ }^{89}$

\section{The "second" pregnancy of the adolescent}

Compared to older women, adolescents who have had a preterm delivery have an increased rate of recurrent adolescent pregnancy. This is especially true among those aged 16 years or less, even after adjustment for socio-economic factors. ${ }^{90} \mathrm{In}$ England and Wales, the number of repeat abortions has risen steadily from 1991 to 2007 in women under 20 years. ${ }^{91}$ This failure of the healthcare system to prevent repeat adolescent pregnancies has been attributed to low contraceptive use as well as the failure of informative and educational support programs directed towards this goal. Therefore, first-time pregnant teenagers should receive direct support to prevent a second pregnancy. Teens who receive adequate prenatal care and family support may be more successful at avoiding recurrent pregnancies than those who are already single mothers or do not know the father of their child. The key to success is modifying behaviors in order to prevent a second pregnancy. ${ }^{92}$ In a Swedish population-based study, primigravid teen mothers aged 17 or less at first birth, experienced a significantly larger reduction of very and moderately preterm births in second pregnancy, as compared with mothers aged $20-24 .{ }^{93}$

An additional study among American teenagers identified predictors of having a low birth weight infant and/or preterm birth in the second pregnancy. When maternal and pregnancy variables (race and other demographical data, maternal tobacco or alcohol use, weight gain during pregnancy, interpregnancy interval) were included in the regression model, it was determined that the provision of appropriate prenatal care reduced the likelihood of low birth weight and preterm birth for the second pregnancy. This provision of care had a stronger impact among unmarried women, those with lower income, and in cases in which the identity of the father is unknown. ${ }^{90}$

\section{Final remarks}

Pregnancy among adolescents is both a medical and a public health concern which may negatively impact the social and physical development of the mother, and affect reproductive quality within a given society. A new family, developed around an adolescent pregnancy, may affect physical, educational, social and emotional maturational aspects of the young mother. Childbirth during adolescence creates lifetime socio-economical disadvantages even among cases with favorable baseline status. ${ }^{92-94}$

Sexual education and contraceptive methods should be available before the risk of becoming pregnant is evident. Programs must necessarily include both girls and boys, often parents, and have a specific socio-culturally oriented framework. ${ }^{95}$ Programs promoting sexual abstinence among adolescents also need to be encouraged, ${ }^{96}$ although studies have reported little or no impact in reducing sexual activity with this strategy. ${ }^{97}$ While sexual activity in the US dropped in both younger teenage girls and boys between 1995 and 2002, there was a concomitant increase in contraceptive use among them..$^{98,99}$ This indicates that adolescents may be delaying sexual activity in order to reduce STDs, unwanted pregnancies, emotional distress or social responsibilities for which they are not prepared. Equivalent data on these matters from less developed areas is still scarce.

An adolescent pregnancy is as much a public health issue as it is a clinical problem requiring appropriate management and support. Early pregnancy and marriage lead to increasing rates of dropping out of school and overall decreases in level of formal education. In some cultural contexts, educational institutions may not be prepared to assume the responsibility of the pregnant adolescent's right to education. Moreover, in some populations, there is a social stigma related to becoming pregnant and sexually active at an early age.

Sexual abuse, STDs, and poverty are key factors surrounding the problem. Programs should be implemented, not only directed at the pregnant adolescent, but also at society to address the perception of the problem and the treatment of the teenager and her condition. Optimal obstetrical care should encourage healthy nutrition and treatment of genital infections as well as emotional support to the adolescent. In order to break the vicious cycle of adolescent pregnancies and the related social and personal disadvantages, a major goal should not be just the care of the current patient, but also the prevention of recurrent adolescent pregnancies.

\section{Author disclosure statement}

No competing financial interests exist.

\section{References}

1. UNICEF. 'A league table of teenage births in rich nations'. Innocenti Report Card No.3. July 2001. UNICEF Innocenti Research Centre. Florence. Available at www.unicef-irc.org/publications/pdf/repcard3e.pdf. Accessed March $2,2011$.

2. World Health Organisation. Adolescent pregnancy. Available at www.who.int/making_pregnancy_safer/topics/adolescent_pregnancy/ en/index.html. Accessed March 2, 2011.

3. Chedraui P. Pregnancy among young adolescents: trends, risk factors and maternal-perinatal outcome. J Perinat Med. 2008;36(3):256-259. 
4. Singh SDJ. Adolescent pregnancy and childbearing: levels and trends in developed countries. Fam Plann Perspect. 2000;32(1): $14-23$.

5. Mayor S. Pregnancy and childbirth are leading causes of death in teenage girls in developing countries. BMJ. 2004;328(7499):1152.

6. Wildman K, Bouvier-Colle MH; MOMS Group. Maternal mortality as an indicator of obstetric care in Europe. BJOG. 2004;111(2):164-169.

7. Ronsmans C, Graham WJ. Lancet Maternal Survival Series steering group. Maternal mortality: who, when, where, and why. Lancet. 2006;368(9542):1189-1200.

8. Walt V. Death in birth. Time. 2008;172:48-52.

9. Chedraui P, Van Ardenne R, Wendte JF, Quintero JC, Hidalgo L. Knowledge and practice of family planning and HIV-prevention behaviour among just delivered adolescents in Ecuador: the problem of adolescent pregnancies. Arch Gynecol Obstet. 2007;2762(2): 139-144.

10. Pérez-López FR, Chedraui P, Cuadros-López JL. Bone mass gain during puberty and adolescence: Deconstructing gender characteristics. Curr Med Chem. 2010;175(5):2010;453-466.

11. Alan Guttmacher Institute. Into a new world: young women's sexual and reproductive lives. New York: AGI; 1998.

12. Paul K, Boutain D, Manhart L, Hitti J. Racial disparity in bacterial vaginosis: the role of socioeconomic status, psychosocial stress, and neighborhood characteristics, and possible implications for preterm birth. Soc Sci Med. 2008;67(5):824-833.

13. National Campaign to Prevent Teen and Unplanned Pregnancy. 2007. Available at www.thenationalcampaign.org/resources/birthdata/. Accessed March 2, 2011.

14. Unplanned pregnancies in the United Sates. May 2008. National Campaign to Prevent Teen and Unplanned Pregnancy. Available at www. thenc.org/resources/pdf/briefly-unplanned-in-the-united-states.pdf. Accessed March 2, 2011.

15. Institute for family policies. Report on the evolution of the family in Europe 2009. Available at www.ipfe.org/Report_evolution_on_the_family_in_Europe_2009.pdf. Accessed March 2, 2011.

16. Molina R, Gonzalez E, Luengo X, Molina T, Toledo V, Campos W. La adolescente embarazada en Chile y su atención médica. The pregnant adolescent in Chile, and her medical care. In: Alfredo Hidalgo San Martin, editor. Salud, sexualidad y reproduccion en la adolescencia: seminario internacional. Guadalajara, Mexico: Universidad de Guadalajara; 1996:151-165.

17. Guijarro S, Naranjo J, Padilla M, Gutiérez R, Lammers C, Blum RW. Family risk factors associated with adolescent pregnancy: study of a group of adolescent girls and their families in Ecuador. J Adolesc Health. 1999;25(2):166-172.

18. Goicolea I, Wulff M, Öhman A, San Sebastian M. Risk factors for pregnancy among adolescent girls in Ecuador's Amazon basin: a casecontrol study. Rev Panam Salud Publica. 2009;26(3):221-228.

19. Ministerio de Salud Publica (EC). Plan Nacional de Prevención del embarazo en la adolescencia. Quito: MSP; 2008.

20. Olausson PO, Cnattingius S, Haglund B. Teenage pregnancies and risk of late fetal death and infant mortality. BJOG. 1999;106(2):116-121.

21. Kirchengast S, Hartmann B. Impact of maternal age and maternal somatic characteristics on newborn size. Am J Hum Biol. 2003;15(2): 220-228.

22. World Health Organisation. The World Health Report 1998. Life in the 21st century: a vision for all. WHO. Geneva; 1998:97.

23. Conde-Agudelo A, Belizan JM, Lammers C. Maternal perinatal morbidity and mortality associated with adolescent pregnancy in Latin America: cross sectional study. Am J Obstet Gynecol. 2005;192(2):342-349.

24. Mollborn S, Morningstar E. Investigating the relationship between teenage childbearing and psychological distress using longitudinal evidence. J Health Social Behav. 2009;50(3):310-326.

25. Salazar-Pousada D, Arroyo D, Hidalgo L, Pérez-López FR, Chedraui P. Depressive symptoms and resilience among pregnant adolescents: a case-control study. Obstet Gynecol Int. 2010:Article ID 952493.
26. Geist RR, BeythY, Shashar D, Beller U, Samueloff A. Perinatal outcome of teenage pregnancies in a selected group of patients. J Pediatr Adolesc Gynecol. 2006;19(3):189-193.

27. Santos GH, Martins G, Sousa S, Batalha J. Impact of maternal age on perinatal outcomes and mode of delivery. Rev Bras Ginecol Obstet. 2009;31(7):326-334.

28. Nkwabong E, Fomulu JN. Adolescent pregnancies and deliveries: problems encountered. Trop Doct. 2009;39(1):9-11.

29. Buitendijk SE, van Enk A, Oosterhout R, Ris M. Obstetrical outcome in teenage pregnancies in The Netherlands. Ned Tijdschr Geneeskd. 1993;137(49):2536-2540.

30. Leppert PC, Namerow PB, Barker D. Pregnancy outcomes among adolescent and older women receiving comprehensive prenatal care. J Adolesc Health Care. 1986;7(2):112-117.

31. Perry RL, Mannino B, Hediger ML, Scholl TO. Pregnancy in early adolescence: are there obstetric risks? J Matern Fetal Med. 1996;5(6): 333-339.

32. Scholl TO, Hediger ML, Belsky DH. Prenatal care and maternal health during adolescent pregnancy: a review and meta-analysis. J Adolesc Health. 1994;15(6):444-456.

33. Mahfouz AA, el-Said MM, al-Erian RA, Hamid AM. Teenage pregnancy: are teenagers a high risk group? Eur J Obstet Gynecol Reprod Biol. 1995;59(1):17-20.

34. Vélez NM, García IE, García L, Valcárcel M. The use of illicit drugs during pregnancy among mothers of premature infants. $P R$ Health Sci J. 2008;27(3):209-212.

35. Cornelius MD, Geva D, Day NL, Cornelius JR, Taylor PM. Patterns and covariates of tobacco use in a recent sample of pregnant teenagers. J Adolesc Health. 1994;15(7):528-535.

36. Padgett DI, Selwyn BJ, Kelder SH. Ecuadorian adolescents and cigarette smoking: A cross-sectional survey. Rev Panam Salud Publica. 1998;4(2):87-93.

37. Lewis LN, Hickey M, Doherty DA, Skinner SR. How do pregnancy outcomes differ in teenage mothers? A Western Australian study. Med J Aust. 2009;190(10):537-541.

38. Thame M, Osmond C, Bennett F, Wilks R, Forrester T. Fetal growth is directly related to maternal anthropometry and placental volume. Eur J Clin Nutr. 2004;58(6):894-900.

39. Ehrenberg HM, Dierker L, Milluzzi C, Mercer BM. Low maternal weight, failure to thrive in pregnancy, and adverse pregnancy outcomes. Am J Obstet Gynecol. 2003;189(6):1726-1730.

40. Inskip HM, Crozier SR, Godfrey KM, Borland SE, Cooper C, Robinson SM. Southampton Women's Survey Study Group. Women's compliance with nutrition and lifestyle recommendations before pregnancy: general population cohort study. BMJ. 2009;338:b481.

41. Crozier SR, Robinson SM, Godfrey KM, Cooper C, Inskip HM. Women's dietary patterns change little from before to during pregnancy. J Nutr. 2009;139(10):1956-1963.

42. Siega-Riz AM, Adair LS, Hobel CJ. Maternal underweight status and inadequate rate of weight gain during the third trimester of pregnancy increases the risk of preterm delivery. J Nutr. 1996;126(1): $146-153$.

43. Berenson AB, Wiemann CM, Rowe TF, Rickert VI. Inadequate weight gain among pregnant adolescents: risk factors and relationship to infant birth weight. Am J Obstet Gynecol. 1997;176(6):1220-1224.

44. Casanueva E, Roselló-Soberón ME, De-Regil LM, Argüelles MC, Céspedes MI. Adolescents with adequate birth weight newborns diminish energy expenditure and cease growth. J Nutr. 2006;136(10): 2498-2501.

45. Stevens-Simon C, McAnarney ER. Adolescent maternal weight gain and low birth weight: a multifactorial model. Am J Clin Nutr. 1998;47(6): 948-953.

46. Sánchez A, Pontiles M, Meertens L, Solano L. Evaluación nutricional antropométrica de la madre en el post-parto inmediato y de su recién nacido. Informe presentado al Centro de Desarrollo Cientifico y Humanistico de la Universidad de Carabobo. CDCHT-UC, Valencia, Venezuela, 1998. 
47. Dufour D, Reina JC, Spurr GB. Energy intake and expenditure of free-living, pregnant Colombian women in an urban setting. Am J Clin Nutr. 1999;70(2):269-276.

48. Fujimori E, Vianna de Oliveira IM, Nuñez de Cassana LM, Cornbluth S. Estado nutricional de gestantes adolescentes en Sao Paulo, Brasil. Arch Latinoam Nutr. 1997;47(4):305-310.

49. Mavalankar DV, Trivedi CC, Gray RH. Maternal weight, height and risk of poor pregnancy outcome in Ahmedabad, India. Indian Pediatr. 1994;31(10):1205-1212.

50. Mahavarkar SH, Madhu CK, Mule VD. A comparative study of teenage pregnancy. J Obstet Gynaecol. 2008;28(6):604-607.

51. Lone FW, Qureshi RN, Emanuel F. Maternal anaemia and its impact on perinatal outcome. Trop Med Int Health. 2004;9(4):486-490.

52. Kidanto HL, Mogren I, Lindmark G, Massawe S, Nystrom L. Risks for preterm delivery and low birth weight are independently increased by severity of maternal anaemia. S Afr Med J. 2009;99(2):98-102.

53. Bondevik GT, Lie RT, Ulstein M, Kvåle G. Maternal hematological status and risk of low birth weight and preterm delivery in Nepal. Acto Obstet Gynecol Scand. 2001;80(5):402-408.

54. Méndez Estrada RO, Pacheco B, Noriega Verdugo H, Quihui L, Morales G, Valencia ME. Prevalence of iron deficiency and iron deficiency anemia in pregnant adolescents from northwest Mexico, 2007-2008. Arch Latinoam Nutr. 2009;59(2):147-151.

55. Baker PN, Wheeler SJ, Sanders TA, et al. A prospective study of micronutrient status in adolescent pregnancy. Am J Clin Nutr. 2009;89(4): $1114-1124$.

56. Allen LH. Biological mechanisms that might underlie iron's effects on fetal growth and preterm birth. $J$ Nutr. 2001;131(2S-2): 581S-589S.

57. Lockwood CJ. Stress-associated preterm delivery: the role of corticotropin-releasing hormone. Am J Obstet Gynecol. 1999;180(1 Pt 3): S264-S266.

58. Herrmann TS, Siega-Riz AM, Hobel CJ, Aurora C, Dunkel-Schetter C. Prolonged periods without food intake during pregnancy increase risk for elevated maternal corticotropin-releasing hormone concentrations. Am J Obstet Gynecol. 2001;185(2):403-412.

59. Pérez-López FR, Fernández-Alonso AM, Ferrando-Marco P, SalmerónGonzález MD, Dionis-Sánchez EC, Fiol-Ruiz G, et al. First trimester serum 25-hydroxyvitamin D status and factors related to lower levels in gravids living in the Spanish Mediterranean coast. Reprod Sci. 2011. In press. [Epub Feb 1 2011].

60. Pérez-López FR. Vitamin D: the secosteroid hormone and human reproduction. Gynecol Endocrinol. 2007;23(1):13-24.

61. Lucas RM, Ponsonby AL, Pasco JA, Morley R. Future health implications of prenatal and early-life vitamin D status. Nutr Rev. 2008;66(12): $710-720$

62. Perez-Lopez FR, Pérez-Roncero G, López-Baena MT. Vitamin D and adolescent health. Adolescent Health, Medicine and Therapeutics. 2010;1:1-8. http://www.dovepress.com/getfile.php?fileID=5716 [last accessed 30/01/2011].

63. Reis FM, Fadalti M, Florio P, Petraglia F. Putative role of placental corticotropin-releasing factor in the mechanisms of human parturition. J Soc Gynecol Investig. 1999;6(3):109-119.

64. Briggs MM, Hopman WM, Jamieson MA. Comparing pregnancy in adolescents and adults: obstetric outcomes and prevalence of anemia. J Obstet Gynaecol Can. 2007;29(7):546-555.

65. Dubicke A, Akerud A, Sennstrom M, et al. Different secretion patterns of matrix metalloproteinases and IL-8 and effect of corticotropin-releasing hormone in preterm and term cervical fibroblasts. Mol Hum Reprod. 2008;14(11):641-617.

66. Glynn LM, Schetter CD, Hobel CJ, Sandman CA. Pattern of perceived stress and anxiety in pregnancy predicts preterm birth. Health Psychol. 2008;27(1):43-51.

67. Bánhidy F, Acs N, Puho EH, Czeizel AE. Rate of preterm births in pregnant women with common lower genital tract infection: a population-based study based on the clinical practice. J Matern Fetal Neonatal Med. 2009;22(5):410-418.
68. Ebersole JL, Novak MJ, Michalowicz BS, et al. Systemic immune responses in pregnancy and periodontitis: relationship to pregnancy outcomes in the Obstetrics and Periodontal Therapy (OPT) study. J Periodontol. 2009;80(6):953-960.

69. Kim MJ, Romero R, Gervasi MT, et al. Widespread microbial invasion of the chorioamniotic membranes is a consequence and not a cause of intra-amniotic infection. Lab Invest. 2009;89(8):924-936.

70. Mazor-Dray E, Levy A, Schlaeffer F, Sheiner E. Maternal urinary tract infection: is it independently associated with adverse pregnancy outcome? J Matern Fetal Neonatal Med. 2009;22(2):124-128.

71. Stevens-Simon C, Barrett J, McGregor JA, French J, Persutte W. Short cervix: a cause of preterm delivery in young adolescents? J Matern Fetal Med. 2000;9(6):342-347.

72. Olausson PO, Cnattingius S, Haglund B. Does the increased risk of preterm delivery in teenagers persist in pregnancies after the teenage period? BJOG. 2001;108(7):721-725.

73. Svare JA, Schmidt H, Hansen BB, Lose G. Bacterial vaginosis in a cohort of Danish pregnant women: prevalence and relationship with preterm delivery, low birthweight and perinatal infections. BJOG. 2006;113(12):1419-1425.

74. Novy MJ, Duffy L, Axthelm MK, et al. Ureaplasma parvum or Mycoplasma hominis as sole pathogens cause chorioamnionitis, preterm delivery, and fetal pneumonia in rhesus macaques. Reprod Sci. 2009;16(1):56-70.

75. Dudley DJ. Immunoendocrinology of preterm labor: the link between corticotropin-releasing hormone and inflammation. Am J Obstet Gynecol. 1999;180:S251-S256.

76. Hedegaard M, Henriksen TB, Sabroe S, Secher NJ. Psychological distress in pregnancy and preterm delivery. BMJ. 1993;307(6898):234-239.

77. Dole N, Savitz DA, Hertz-Picciotto I, Siega-Riz AM, McMahon MJ, Buekens P. Maternal stress and preterm birth. Am J Epidemiol. 2003; 157(1):14-24.

78. Kara F, Uygur D, Yesildaglar N. Adolescent pregnancy and cesarean delivery. Int J Gynaecol Obstet. 2003;81(2):231-232.

79. Usta IM, Zoorob D, Abu-Musa A, Naassan G, Nassar AH. Obstetric outcome of teenage pregnancies compared with adult pregnancies. Acta Obstet Gynecol Scand. 2008;87(2):178-183.

80. Hidalgo LA, Chedraui PA, Chavez MJ. Obstetrical and neonatal outcome in young adolescents of low socio-economic status: a case control study. Arch Gynecol Obstet. 2005;271(3):207-211.

81. Unfer V, Piazze Garnica J, Di Benedetto MR, Costabile L, Gallo G, Anceschi MM. Pregnancy in adolescents. A case control study. Clin Exper Obstet Gynecol. 1995;22(2):161-164.

82. Bozkaya H, Mocan H, Usluca H, Beşer E, Gümüştekin D. A retrospective analysis of adolescent pregnancies. Gynecol Obstet Invest. 1996;42(3):146-150.

83. Chan BC, Lao TT. Maternal height and length of gestation: does this impact on preterm labour in Asian women? Aust NZJ Obstet Gynaecol. 2009;49(4):388-392.

84. Lao TT, Ho LF. Relationship between preterm delivery and maternal height in teenage pregnancies. Hum Reprod. 2000;15(2):463-468.

85. Chan BC, Lao TT. The impact of maternal height on intrapartum operative delivery: a reappraisal. J Obstet Gynaecol Res. 2009;35(2):307-314.

86. Rah JH, Christian P, Shamim AA, Arju UT, Labrique AB, Rashid M. Pregnancy and lactation hinder growth and nutritional status of adolescent girls in rural Bangladesh. $J$ Nutr. 2008;138(8):1505-1511.

87. Subramanian SV, Ackerson LK, Davey Smith G, John NA. Association of maternal height with child mortality, anthropometric failure, and anemia in India. JAMA. 2009;301(16):1691-1701.

88. Thurman AR, Hulsey T. Pregnant adolescents' preferences for labor pain management. South Med J. 2004;97(10):964-967.

89. Polley LS, Van de Ven CJM. The pregnant teenager. In: Datta S, editor. Anesthetic and obstetric management of high-risk pregnancy. New York: Springer-Verlag; 2004:45-52.

90. Partington SN, Steber DL, Blair KA, Cisler RA. Second births to teenage mothers: risk factors for low birth weight and preterm birth. Perspect Sex Reprod Health. 2009;41(2):101-109. 
91. Collier J. The rising proportion of repeat teenage pregnancies in young women presenting for termination of pregnancy from 1991 to 2007. Contraception. 2009;79(5):393-396.

92. Maynard RA. The study, the context and findings in brief. In: Maynard RA, editor. Kids having kids: economic costs and social consequences of teen pregnancy. Washington: Urban Institute Press; 1997:1-22.

93. Olausson PO, Haglund B, Weitoft GR, Cnattingius S. Teenage childbearing and long-term socioeconomic consequences: a case study in Sweden. Fam Plann Perspect. 2001;33(2):70-74.

94. Hobcraft J, Kiernan K. Childhood poverty, early motherhood and adult social exclusion. Br J Sociol. 2001;52(3):495-517.

95. Johnson P, Johnson J, Heurich S, et al. The Africentric Transtheoretical model in a school-based pregnancy prevention program. ABNF J. 1998;9(2):40-44.
96. Khouzam HR. Promotion of sexual abstinence: reducing adolescent sexual activity and pregnancies. South Med J. 1995;88(7): 709-711.

97. Kohler PK, Manhart LE, Lafferty WE. Abstinence-only and comprehensive sex education and the initiation of sexual activity and teen pregnancy. J Adolesc Health. 2008;42(4):344-351.

98. US Department of Health and Human Services (HHS). Teenagers in the United States: Sexual Activity, Contraceptive Use, and Childbearing, 2002. Available at www.cdc.gov/nchs. Accessed March 2, 2011.

99. US Department of Health and Human Services (HHS). Use of Contraception and Use of Family Planning Services in the United States, 1982-2002. Available at www.cdc.gov/nchs. Accessed March 2, 2011 .
Open Access Journal of Contraception

\section{Publish your work in this journal}

Open Access Journal of Contraception is an international, peerreviewed, open access, online journal, publishing original research, reports, reviews and commentaries on all areas of contraception. In addition to clinical research, demographics and health-related aspects, the journal welcomes new findings in animal and preclinical studies

\section{Dovepress}

relating to understanding the biological mechanisms and practical development of new contraceptive agents. The manuscript management system is completely online and includes a very quick and fair peer-review system. Visit http://www.dovepress.com/testimonials.php to read real quotes from published authors. 